\title{
Duodenal Stromal Tumor with Neural Differentiation
}

\author{
Akitaka Tanaka, Makoto Hoshino, Tomihiro Hayakawa, Yasutaka KamiYa, Takayuki Ohiwa, \\ Asamitsu Hirano, Tomoyuki Kumai, Makoto MiyaJi, Toshihiko Takeuchi and Tadaaki Eimoto*
}

\begin{abstract}
A 49-year-old woman was admitted to our hospital for detailed evaluation of an abdominal mass. Ultrasonography and computed tomography revealed two tumors, one a submucosal lesion of the duodenal second portion and the other a left adrenal tumor. Angiography showed that the tumors were hypervascular. Both tumors were removed surgically and examined histologically using hematoxylin-eosin staining. The duodenal tumor $(10 \times 6 \times 5 \mathrm{~cm})$ was initially diagnosed as a schwannoma, but immunohistochemical studies showed that it was $\mathbf{S - 1 0 0}$ protein negative and neuron-specific enolase positive. Therefore, this tumor was identified as a stromal tumor with neural differentiation. The left adrenal tumor was a nonfunctioning adenoma.

(Internal Medicine 32: 72-76, 1993)
\end{abstract}

Key words: immunohistochemical study, S-100 protein, neuron-specific enolase, adrenal tumor

\section{Introduction}

Neurogenic tumors of the duodenum are relatively rare and are usually classified as schwannomas or neurofibromas. We recently detected a submucosal tumor $(10 \times 6 \times 5 \mathrm{~cm})$ of the duodenal second portion. When this tumor was examined histologically after surgery, hematoxylin-eosin (HE) staining strongly indicated that it was a schwannoma. However, when examined immunohistochemically, the tumor was $\mathrm{S}-100$ protein negative and neuron-specific enolase (NSE) positive. Based on these results, the present case was classified as a stromal tumor with neural differentiation.

\section{Case Report}

A mass in the right epigastric region was detected in a 49-year-old woman by abdominal ultrasonography (US). She was admitted to our department for detailed evaluation. She had no symptoms and no abdominal swelling or tenderness. Laboratory data on admission revealed no abnormalities (Table 1 ). Tumor markers and endocrinological tests were normal. However, US carried out after admission, revealed a well-demarcated, oval and low-echoic mass with high internal echoes (about $10 \mathrm{~cm}$ in size) between the liver and the right kidney and a well-demarcated mass $(4 \times 3.5 \mathrm{~cm})$ in the left adrenal gland (Fig. 1). Abdominal computed tomography $(\mathrm{CT})$ revealed a round mass in the ventral region of the right kidney; it was well enhanced in the marginal areas but not in the interior. A round, homogeneously enhanced mass in the left adrenal gland was also detected (Fig. 2). Upper gastrointestinal radio-

Table 1. Laboratory Data on Admission

\begin{tabular}{|c|c|c|c|}
\hline \multirow{2}{*}{\multicolumn{2}{|c|}{$\begin{array}{l}\text { Urinalysis n.p. } \\
\text { Stool occult blood }(-)\end{array}$}} & \multicolumn{2}{|l|}{ Serological } \\
\hline & & CRP & $0.3 \mathrm{mg} / \mathrm{dl}$ \\
\hline \multicolumn{2}{|c|}{ Peripheral blood } & ESR & $35 \mathrm{~mm}(1 \mathrm{hr})$ \\
\hline WBC & $4800 / \mathrm{mm}^{3}$ & CEA & $3.1 \mathrm{ng} / \mathrm{ml}$ \\
\hline $\mathrm{RBC}$ & $352 \times 10^{4} / \mathrm{mm}^{3}$ & CA19-9 & $10 \mathrm{U} / \mathrm{ml}$ \\
\hline $\mathrm{Hb}$ & $10.3 \mathrm{~g} / \mathrm{dl}$ & AFP & $5 \mathrm{ng} / \mathrm{ml}$ \\
\hline Plt & $22.5 \times 10^{4} / \mathrm{mm}^{3}$ & & \\
\hline \multicolumn{2}{|c|}{ Blood chemistry } & Endocrine tests & \\
\hline T.P & $6.2 \mathrm{~g} / \mathrm{dl}$ & (Plasma) & \\
\hline Alb & $4.1 \mathrm{~g} / \mathrm{dl}$ & Epinephrine & $29 \mathrm{pg} / \mathrm{ml}$ \\
\hline T.B. & $0.4 \mathrm{mg} / \mathrm{dl}$ & Norepinephrine & $86 \mathrm{pg} / \mathrm{ml}$ \\
\hline GOT & $16 \mathrm{U} / 1$ & Renin & $0.2 \mathrm{ng} / \mathrm{ml} . \mathrm{hr}$ \\
\hline GPT & $11 \mathrm{U} / \mathrm{l}$ & Aldosterone & $6 \mathrm{ng} / \mathrm{dl}$ \\
\hline LDH & $122 \mathrm{U} / 1$ & Cortisol & $16.8 \mu \mathrm{g} / \mathrm{dl}$ \\
\hline ALP & $110 \mathrm{U} / 1$ & (Urine) & \\
\hline rGTP & $8 \mathrm{U} / 1$ & Epinephrine & $6.7 \mu \mathrm{g} /$ day \\
\hline ChE & $275 \mathrm{U} / 1$ & Norepinephrine & $39.2 \mu \mathrm{g} /$ day \\
\hline BUN & $13 \mathrm{mg} / \mathrm{dl}$ & VMA & $2.4 \mathrm{mg} /$ day \\
\hline Crea & $0.8 \mathrm{mg} / \mathrm{dl}$ & & \\
\hline $\mathrm{Na}$ & $139 \mathrm{mEq} / 1$ & Chest X-P & n.p. \\
\hline $\mathrm{K}$ & $3.6 \mathrm{mEq} / \mathrm{l}$ & ECG & W.N.L. \\
\hline T. Chol & $188 \mathrm{mg} / \mathrm{dl}$ & & \\
\hline Amylase & $240 \mathrm{U} / 1$ & & \\
\hline
\end{tabular}

From the First Department of Internal Medicine and *the Department of Pathology, Nagoya City University Medical School, Nagoya Received for publication May 14, 1992; Accepted for publication November 27, 1992

Reprint requests should be addressed to Dr. Akitaka Tanaka, the First Department of Internal Medicine, Nagoya City University Medical School, 1 Kawasumi, Mizuho-cho, Mizuho-ku, Nagoya 467, Japan 


\section{Duodenal Neurogenic Tumor}

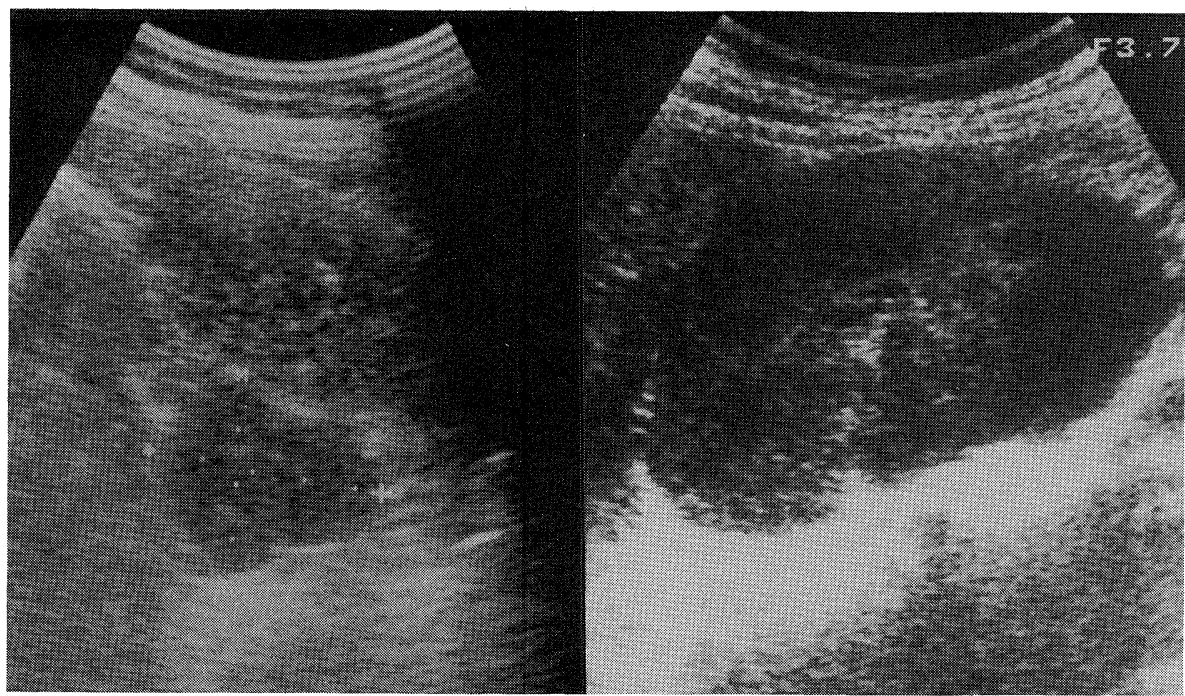

Fig. 1. Ultrasonography of the abdomen revealed an oval low echoic mass (about $10 \mathrm{~cm}$ in size) with high internal echoes (right) and a $4.5 \times 3.5 \mathrm{~cm}$ mass in the left adrenal gland (left).

graphy revealed compression of the duodenal second portion from the right side. A similar compression of the same region was apparent on an X-ray obtained 3
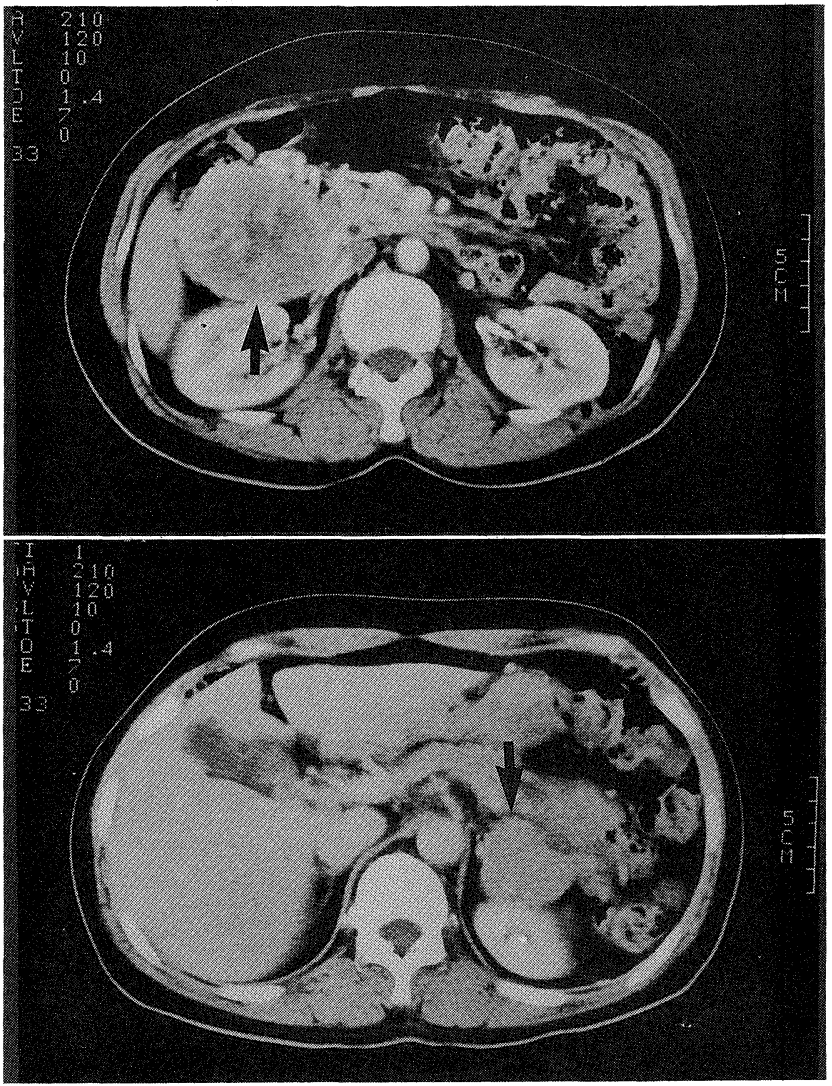

Fig. 2. Computed tomography showed a mass (arrow) with wellenhanced marginal areas in the ventral region of the right kidney (upper) and a homogenously enhanced mass (arrow) in the left adrenal gland (lower). years earlier. A barium enema study revealed downward compression of the right colonic flexor. Hypotonic radiography of the duodenum revealed compression of the second portion from the right side (Fig. 3). Endoscopy revealed marked stenosis of the duodenal second portion, with no accompanying mucosal abnormalities. Arteriograms of the arterial phase revealed dilatation of the gastroduodenal artery and dilatation, meandering

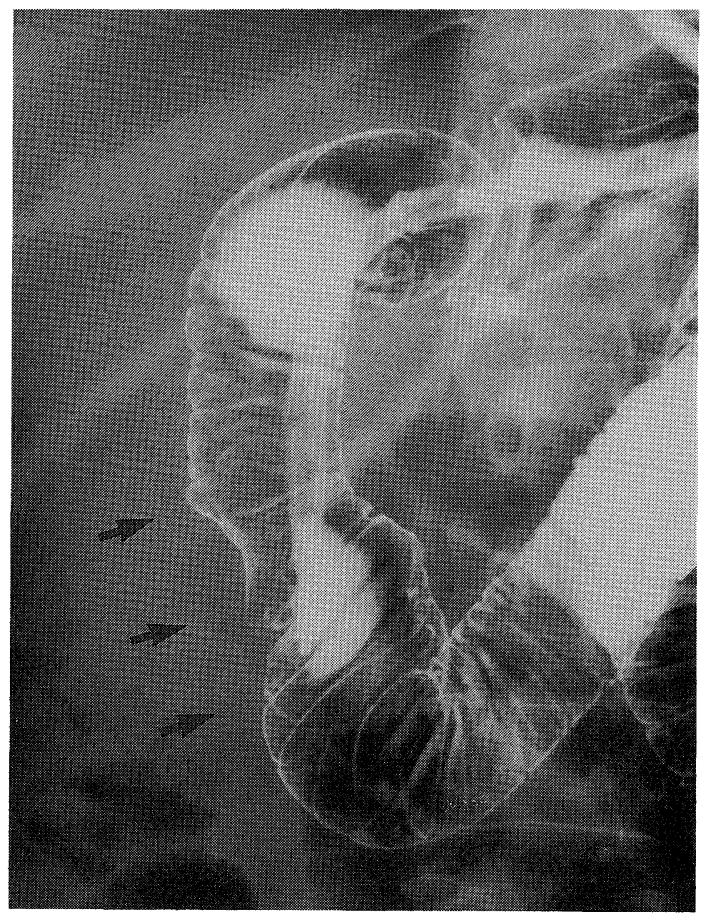

Fig. 3. Hypotonic radiography of the duodenum showed compression (arrows) of the second portion from the right side. 
and hyperplasia of the tumor vessels (Fig. 4). Arteriograms of the capillary and venous phases revealed nonhomogeneous tumor staining. The lower portion of the

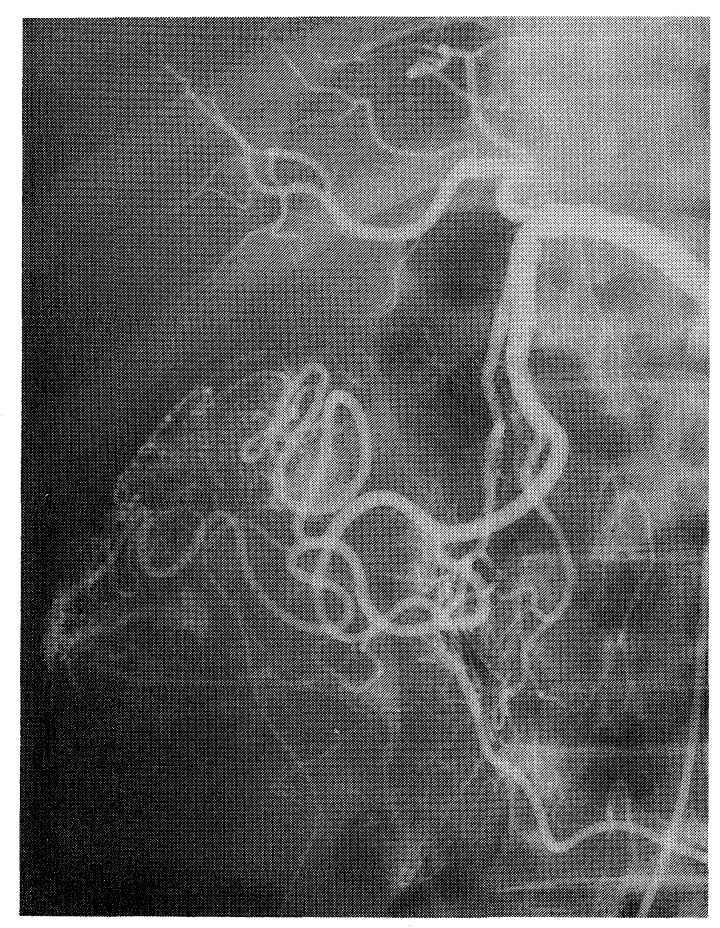

Fig. 4. Angiography showed dilatation of the gastroduodenal artery and dilatation, meandering and hyperplasia of the tumor vessels.

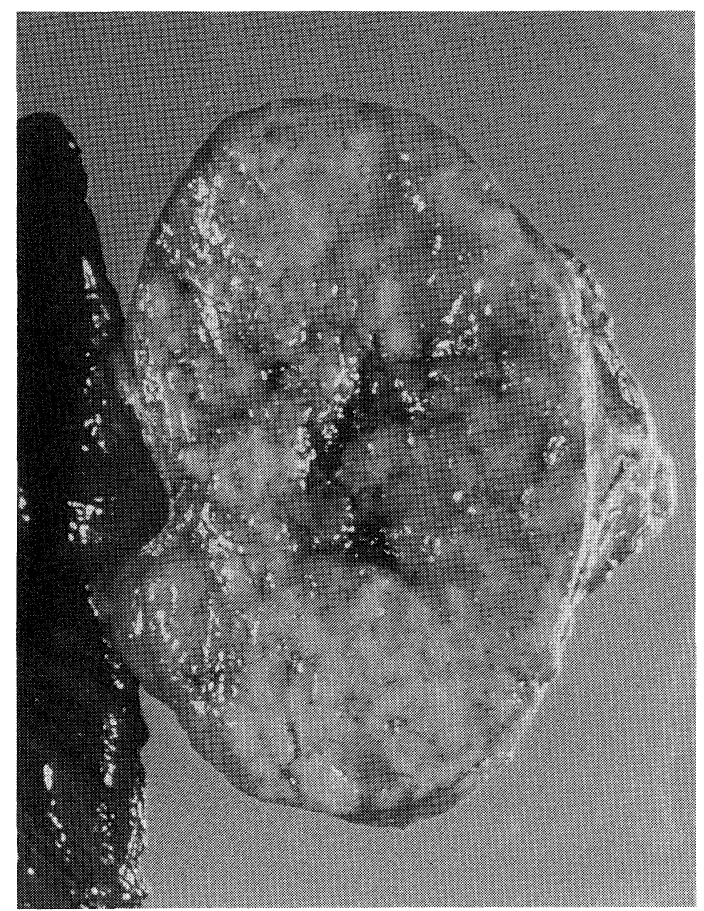

Fig. 5. The cut section of the duodenal tumor was gray, solid and necrotic at the center. tumor was supplied by the right colic artery. Aortography disclosed faint staining caused by filling via the left middle adrenal artery in the same regions in which masses were identified by CT and US.

The resected duodenal tumor measured $10 \times 6 \times 5 \mathrm{~cm}$. Although there was some adhesion to the duodenum, it could be freed manually along its full length except for a $1.5 \mathrm{~cm}$ portion. It originated from proper muscle layers in the duodenum. The cut surface of the tumor was gray and necrotic at the center (Fig. 5). The left adrenal tumor measured $4 \times 4 \times 1.5 \mathrm{~cm}$ and was uniformly yellow on the cut surface. HE staining of the duodenal tumor showed a palisading arrangement of thin spindle cells containing oval nuclei, suggesting that it was a schwannoma (Fig. 6). Immunohistochemical

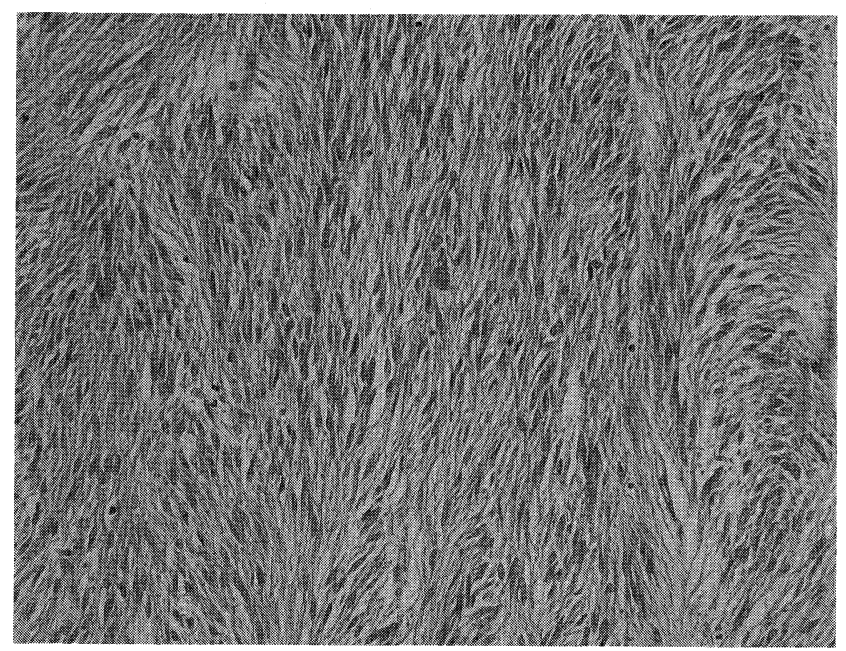

Fig. 6. Microscopic view of the duodenal tumor. Tumor cells were thin and spindle-shaped forming palisades (HE stain, $\times 100$ ).

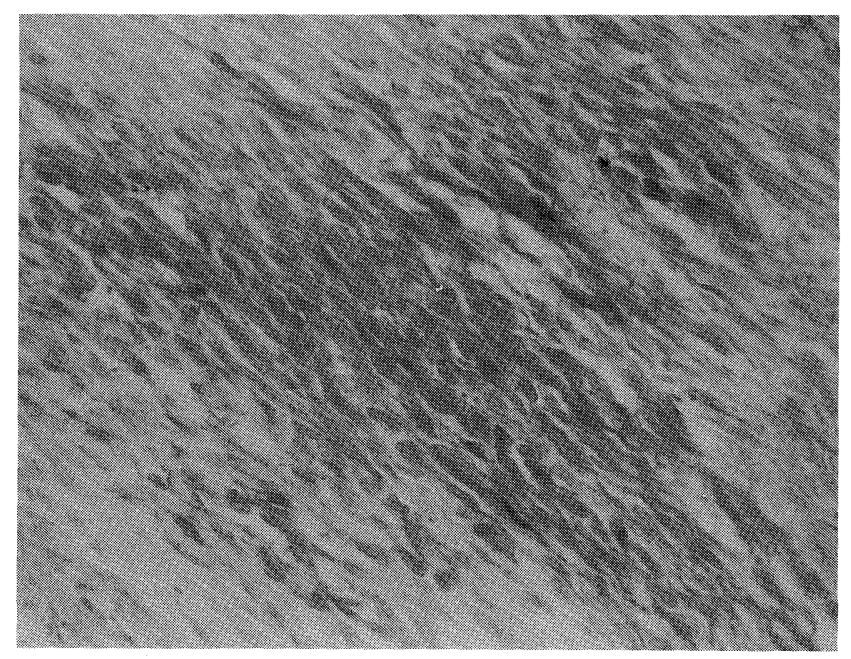

Fig. 7. Semi-final section of the duodenal tumor illustrated in Fig. 6 stained immunohistochemically with neuron-specific enolase (Note positive staining, $\times 200)$. 
study showed that the tumor was negative for desmin (DES), smooth muscle actin (SMA) and S-100 protein and positive for NSE (Fig. 7). Therefore, we reclassified the duodenal tumor as a stromal tumor with neural differentiation. Histological examination showed that the adrenal tumor was an adenoma.

\section{Discussion}

It was difficult to classify the large tumor which was chiefly supplied by the gastroduodenal artery, preoperatively. By its appearance, this could have been a smooth muscle tumor, a neurogenic tumor, a malignant lymphoma, a lipoma or a hemangioma. Angiography and CT findings suggested a smooth muscle tumor, neurogenic tumor, or malignant lymphoma. Angiographic findings of malignant lymphomas generally show poor vascularity, poor tumor vessel formation, and hardly any tumor staining, although hypervascularity has been seen in rare cases $(1,2)$. Therefore, the hypervascularity found in the present study appeared to indicate either a smooth muscle tumor or a neurogenic tumor. Further differential diagnosis was impossible before surgery.

The left adrenal tumor showed only faint staining on aortography. We first considered the possibility that this tumor was a metastasis from the duodenal lesion or a component of a multiple endocrine neoplasm. However, the lack of other metastasis and the absence of abnormal hormone levels suggested that these possibilities were unlikely. This tumor was histologically classified as a non-functioning adenoma.

Neurogenic duodenal tumors are relatively rare. River et al (3) reported that $90(6.4 \%)$ of 1399 benign tumors of the small intestine were neurogenic. Sivak et al (4) similarly reported that only $44(3.2 \%)$ of 1481 small intestinal tumors were neurogenic, and found that 10 of 28 neurogenic tumors of the small intestine examined were of duodenal origin.

Neurogenic tumors of the gastrointestinal tract have been classified as schwannomas or neurofibromas. In the present case, the duodenal tumor was classified as a schwannoma by three pathologists based on the palisading arrangement of spindle cells visualized with HE staining. However, the tumor was negative for S-100 protein, a calcium-bound protein detected in the Schwann cells or in the outermost layer of the myelin sheath (5-9), indicating that it was not a schwannoma. Immunohistochemical study showed that the tumor was also negative for DES and SMA, which are specific to tumors of smooth muscle origin $(9,10)$, and positive for NSE, an index of neurogenicity (11-14). These findings confirmed the neurogenic nature of the tumor.

NSE is present in high concentrations in neurons and neuroendocrine cells and has recently been investigated as a neural marker (11-14). NSE has also been detected in some non-neuroendocrine tumors using immuno- cytochemical and radioimmunoassay methods (15-17). NSE is sometimes disparaged as nonspecific enolase. SMA is a sensitive smooth muscle marker; although it also reacts with pericytes and myofibroblasts, it is specific in smooth muscle tumors (10). Because of the unclear origin of the tumor in the present case, we described it as a stromal tumor with neural differentiation.

When Newman et al (9) used immunohistochemical methods to examine 90 stromal tumors that had been diagnosed as leiomyomas, leiomyosarcomas, leiomyoblastomas, schwannomas or neurofibromas, they found that $36 \%$ showed neural differentiation, $31 \%$ appeared to be smooth muscule tumors, $20 \%$ manifested bi-directional differentiation, and $13 \%$ were negative for all the markers tested. Only $6.6 \%$ expressed S-100 protein. These results indicate that it is difficult to distinguish spindle cells of a neural origin from spindle cells of a smooth muscle origin by histology. Koyo et al (18) reported that only 2 of 16 Japanese cases of duodenal schwannoma were confirmed to be S-100 protein positive. If all of the cases reported by Koyo et al had been studied immunohistochemically, the diagnosis of schwannoma would probably have been doubtful in some cases.

The tumor in the present case was larger than any of the schwannoma in the 16 Japanese cases described by Koyo et al (18). Schwannoma is often associated with bleeding, which was seen in 10 of their 16 cases. The present case, however, was symptom free. The lack of symptoms in our case, despite the presence of a large tumor, suggests that the tumor is benign and is chiefly an extramural growth. According to Newman et al (9), tumors that are immunohistochemically classified as having a neural phenotype have the best prognosis. Identification of more cases with this tumor type would facilitate review of the relationship between HE-based histological diagnosis and immunohistochemical diagnosis for the purpose of clarifying clinical prognosis.

\section{References}

1) Levin DC, Gordon DH, Kinkhabwala M, Becker JA. Arteriography of retroperitoneal lymphoma. Am J Roentgenol 126: 368, 1976.

2) Takahashi M, Numaguchi $Y$, Kishikawa $T$, Tsukamoto $Y$, Ikeda J, Matsuura K. Angiography of abdominal lymphomas. Nippon Acta Radiol 40: 1, 1980.

3) River L, Silverstein J, Tope JW. Benign neoplasms of the small intestine. Int Abstr Surg 102: 1, 1956.

4) Sivak MV, Sullivan BH, Farmer RG. Neurogenic tumors of the small intestine. Gastroenterology 68: 374, 1975.

5) Isobe $T$, Ishioka $N$, Masuda $T$, Takahashi $Y$, Ganno $S$, Okuyama T. A rapid separation of $S 100$ subunits by high performation liquid chromatography: The subunit compositions of S100 proteins. Biochem Int 6: 419, 1983.

6) Hjermstad BM, Sobin LH, Helwig EB. Stromal tumors of the gastrointestinal tract: Myogenic or neurogenic? Am J Surg Pathol 11: 383, 1987.

7) Mazur MT, Clark HB. Gastric stromal tumours. Reappraisal of 


\section{TANAKA et al}

histogenesis. Am J Surg Pathol 11: 464, 1987.

8) Daimaru $Y$, Kido H, Hashimoto H, Enjoji M. Benign schwannoma of the gastrointestinal tract: A clinicopathologic and immunohistochemical study. Hum Pathol 19: 257, 1988.

9) Newman PL, Wadden C, Fletcher CDM. Gastrointestinal stromal tumours: correlation of immunophenotype with clinicopathological features. J Pathol 164: 107, 1991.

10) Jones H, Steart PV, Du Boulay CEH, Roche WR. Alpha-smooth muscle actin as a marker for soft tissue tumours. A comparison with desmin. J Pathol 162: 29, 1990.

11) Marangos PJ, Zis AP, Clark RL, Goodwin FK. Neuronal, nonneuronal and hybrid forms of enolase in brain: structual, immunological and functional comparisons. Brain Res 150: 117, 1978.

12) Marangos PJ, Schmechol D, Parma AM, Clark RL, Goodwin FK. Measurement of neuron-specific (NSE) and non-neural (NNE) isoenzymes of enolase in rat, monkey and human nervous tissue. J Neurochem 33: 319, 1979.

13) Kato K, Ishiguro Y, Suzuki F, Ito A, Semba R. Distribution of nervous system-specific forms of enolase in peripheral tissues. Brain Res 237: 441, 1982.

14) Yagihashi S, Kimura M, Kurotaki H, et al. Gastric submucosal tumours of neurogenic origin with neuroaxonal and Schwann cell elements. J Pathol 153: 41, 1987.

15) Sheppard MN, Corrin B, Bennet MH, Marangos PJ, Bloom SR, Polak JM. Immunocytochemical localization of neuron specific enolase in small cell carcinomas and carcinoid tumours of the lung. Histopathology 8: 171, 1984.

16) Tapia FJ, Polak JM, Barbosa AJA, et al. Neuron-specific enolase is produced by neuroendocrine tumours. Lancet i: 808, 1981.

17) Pahlman S, Esscher T, Nilsson K. Expression of $\gamma$-subunit of enolase, neuron-specific enolase, in human nonneuroendocrine tumors and derived cell lines. Lab Invest 54: 554, 1986.

18) Koyo $T$, Matsumura $A$, Matsuda $S$, et al. A case report of malignant schwannoma of the duodenum. Gastroenterol Endosc 31: 1842, 1989 (in Japanese, abstract in English). 